\title{
Will US rival strip BTG bare?
}

\section{London}

THE British government's plan to sell British Technology Group (BTG) has returned as a focus of political controversy. The new development is that BTG's principal international competitor, Research Corporation Technologies (RCT) of Tucson, Arizona, is bidding for a stake in BTG. Its involvement has sparked fears - hotly denied by RCT - that it may eventually launch a hostile takeover, with the intention of dismantling BTG and selling its patents.

Both groups specialize in patenting inventions, investing in their development and subsequently selling patent licences to manufacturing and other companies. Although many universities and government laboratories make their own arrangements, both BTG and RCT enjoy a wideranging portfolio of patents, often assigned by academic inventors, so they can group patents together to produce more lucrative licensing packages

Because this market is dominated by the two companies, RCT's interest in BTG raises important questions of competition. And with BTG planning to expand into RCT's home market, having opened a US subsidiary (see Nature 352, 652; 1991), the British Labour party believes that RCT's intention is to emasculate its competitor's US operations.

The Conservative government has said that BTG will be sold to a consortium of investors, with individual members except under undefined "exceptional circumstances" - holding no more than a 15 per cent stake. The formula is supposed to stop BTG falling into the hands of investors who might be tempted to sell off some of its portfolio of patents for short-term profit. The accountants Price Waterhouse, who are handling the sale, have cast a veil of secrecy over the entire process, but it is thought that three consortia now stand as front-runners to buy BTG.

One consortium is headed by BTG's management and staff, headed by chief executive Ian Harvey (see Nature 355, 102; 9 January 1992). A second is led by Sir Ronald Mason, formerly chief scientist at the Ministry of Defence, and comprises a number of industry-linked research associations. But it is a third group, including RCT and led by John Ashworth, director of the London School of Economics, that is now at the centre of a bitter political row. A report in the 26 January Sunday Telegraph, which said that RCT was seeking a 30 per cent shareholding, has horrified BTG's senior managers, and led the opposition Labour Party to demand a government statement on the sale. A Department of Trade and Industry spokesman says the 15 per cent limit will be applied flexibly, but adds that a
30 per cent holding is unlikely to be acceptable.

Labour's science and technology spokesman, Jeremy Bray, believes that RCT wants to curtail BTG's US operations. He points to an earlier approach RCT made to BTG's management, suggesting a joint management buyout. Under this plan - given short shrift by Harvey - BTG would have concentrated on the European market, allowing RCT to dominate in the United States. Bray also argues that the government's 'golden share' in BTG, a majority share that the government says it will retain for five years, to prevent a hostile takeover, offers little

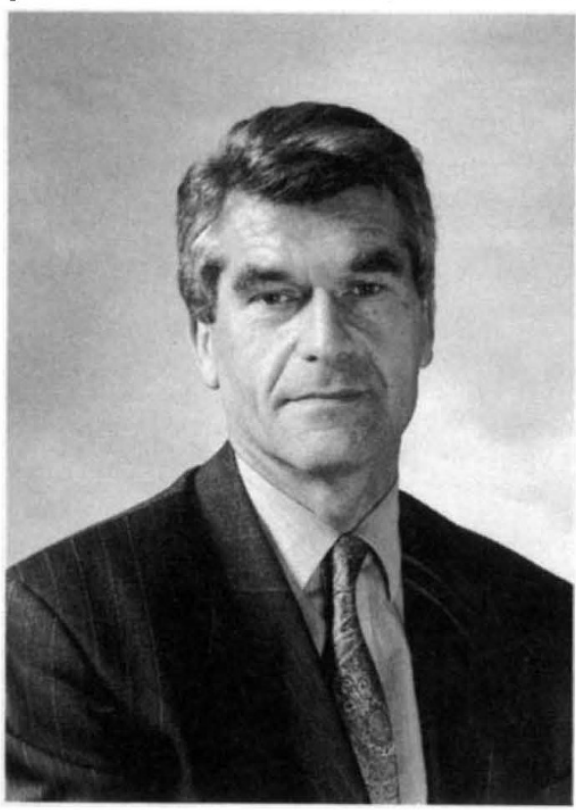

Ashworth sees "xenophobia" in opposition to US buyer for BTG.

protection. A similar golden share, in the Jaguar motor company, was disposed of by the government as the Ford company was allowed to take control of the group.

The concern about RCT extends beyond the Labour party. Peter Doyle, research director of ICI, says that as "a concerned individual", he has to question RCT's intentions. "Do you think this adds to the scope for the licensing of new technologies [to industry], or is it more liable to lead to an elimination of competition?" he asks.

Doyle argues that BTG's present style of operation should be retained and is worried that this might not be the case with RCT as the dominant 'expert' shareholder. There are subtle differences between the two groups' styles. RCT, unlike BTG, is a not-for-profit corporation (which, incidentally, makes it immune to takeover). RCT also runs a much smaller staff than BTG, choosing not to retain in-house patent experts and lawyers, instead employing outside contractors to work on spe- cific projects. RCT's business is also more finely focused on the licensing of technologies from academic institutions. Unlike BTG, it has no strong interest in "corporate licensing' - - selling access to technologies developed by one company to other industrial concerns.

Ashworth says that he would "like to bring over to Britain RCT's style and mode of operation", but denies that RCT's motivation is to protect itself from competition. RCT's president, Gary Munsinger, says that, in any case, BTG-USA is principally concerned with corporate licensing, so the two groups are not serious competitors in the US market. But BTG's medium-term plans include a drive to increase its uptake of technology from US universities, and Munsinger admits that he would like both groups to expand "based on inventions each originates from its own territory". Ashworth can give no firm assurances that BTG-USA would not be closed under his consortium's ownership, before he has studied its finances.

Ashworth's involvement with RCT has enraged the Labour party. During the passage of the B'TG privatization bill through parliament, Labour cooperated with the Committee of Vice-Chancellors and Principals (CVCP) to secure an amendment to ensure that the universities, represented by CVCP, would be consulted about the sale. Labour politicians are incensed that a senior member of the CVCP should now emerge at the head of a bid they see as damaging to BTG.

Ashworth says that he withdrew from all CVCP discussions about B'TG's privatization after he was approached by RCT - and accuses the British opponents of his consortium of barely concealed "xenophobia". Ashworth suggests that they compare RCT's record with that of BTG: RCT returns over 60 per cent of its revenues to its inventors, he says. BTG officials agree that BTG returns a smaller proportion of its licence income to inventors (around 25 per cent), but say that the group invests a far higher proportion of its revenues directly into new technologies - when this is taken into account, BTG's payments into academia compare well with those of RCT.

Even if the RCT-led bid is not successful, the Labour party claims that RCT will have gained commercially-sensitive information about BTG. Last Friday [31 January], Labour industry spokesman Gordon Brown demanded a government statement on "new evidence that BTG is being forced to hand over details of many of [its] technologies". Price Waterhouse have opened a 'data room' where the rival consortia can study documents about BTG to help them prepare their bids, but will not reveal the precise information being made available.

Peter Aldhous 